\title{
Comparison of Nerve-Sparing Radical Hysterectomy and Radical Hysterectomy: a Systematic Review and Meta-Analysis
}

\author{
Zhuowei Xue Xiaolu Zhu Yincheng Teng \\ Department of Obstetrics and Gynaecology, Shanghai Jiao Tong University Affiliated Sixth People's \\ Hospital, Shanghai, People's Republic of China
}

\section{Key Words}

Nerve-sparing radical hysterectomy $\cdot$ Cervical cancer - Bladder dysfunction - Female Sexual Function Index • Systematic review • Meta-analysis

\begin{abstract}
Background/Aims: Radical hysterectomy $(\mathrm{RH})$ for the treatment of cervical cancer frequently caused pelvic organ dysfunctions. This study aimed to compare the results of pelvic organ function and recurrence rate after Nerve sparing radical hysterectomy (NSRH) and $\mathrm{RH}$ treatment through systematic review and meta-analysis. Methods: PubMed, Web of Science and China Knowledge Resource Integrated Database were searched from inception to 25 February 2015. Studies of cervical cancer which reported radical hysterectomy or nerve sparing radical hysterectomy were included. The quality of included studies was evaluated using the guidelines of Cochrane Handbook for Systematic Reviews of Interventions. Statistical analysis was performed using Review Manager 5.3 software (Cochrane Collaboration). Results: A total of 20 studies were finally included. Meta-analysis demonstrated that NSRH was associated with less bladder and anorectal dysfunction than $\mathrm{RH}$. The time to bladder and anorectal function recovery after NSRH was shorter than RH. Patients undergoing NSRH also scored higher than patients undergoing RH at Female Sexual Function Index (FSFI). On the other hand, the local recurrence and overall recurrence rate were similar between NSRH and RH. Conclusion: NSRH may be an effective technique for lowering pelvic organ dysfunction and improving the function recovery without increasing the recurrence rate of cervical cancer.
\end{abstract}

\section{Introduction}

Cervix uteri cancer was the number one cause of cancer deaths in South-East Asia and Africa, while at the global level it ranked 5th of most common cancers among women according to the number of deaths [1]. Radical hysterectomy (RH) was established by Ernst 


\section{Cellular Physiology Cell Physiol Biochem 2016;38:1841-1850 \\ \begin{tabular}{c|c} 
DOI: 10.1159/000443122 & O 2016 The Author(s). Published by S. Karger AG, Basel \\
www.karger.com/cpb
\end{tabular} \\ Xue/Zhu/Teng: Comparison of NSRH and RH}

Wertheim as the classical surgical approach for the treatment of early-stage cervical cancer $[2,3]$. However, the quality of patient's life was hugely influenced after RH due to a high rate of postoperative morbidities involving the pelvic autonomic nerve system, such as bladder dysfunction, colorectal disorder and sexual dissatisfaction [4].

In order to improve cervical cancer survivor's quality of life, nerve-sparing radical hysterectomy (NSRH) preserving the pelvic autonomic nerves was first developed by Japanese gynecologist Takashi Kobayashi [5]. The NSRH technique was then modified and improved by other gynecologists around the world, which became a quite popular surgical approach for cervical cancer treatment during the last two decades [5-7].

Some investigators proposed that NSRH might reduce the incidence of postoperative pelvic organ morbidities, while not reduce the radicality of $\mathrm{RH}$ and increase the recurrence rate $[2,4,8]$. However, there was no large enough randomized clinical trials on this subject to compare the outcomes of NSRH and RH. We reviewed the current randomized and nonrandomized clinical trials to compare the influence of these two surgical techniques on pelvic organ functions and cancer recurrence. We aimed to provide some evidence to decide whether the NSRH technique could be implemented as an effective and safe treatment with less postoperative morbidities for cervical cancer patients through meta-analysis of pooled clinical studies.

\section{Materials and Methods}

This review was prepared according to the Preferred Reporting Items for Systematic Reviews and Meta-Analyses (PRISMA) guidelines [9]. A search of PubMed, Web of Science and China Knowledge Resource Integrated Database was performed for studies published up to 25 February 2015, using the search term "nerve sparing or radical hysterectomy and cervical cancer" without limiting publication language. Reference lists of all available clinical studies were manually searched and reviewed to discover additional relevant data.

We included the following clinical trials: (1) studies compared postoperative pelvic organ dysfunction and recovery after NSRH and RH, including bladder dysfunction, bladder function recovery, anorectal function, anorectal function recovery and sexual function; (2) studies compared local recurrence rate or overall recurrence rate after NSRH and RH. The included clinical trials should have informed consent and ethics committee approval for studies on patients, patient records, or volunteers.

Studies described surgical techniques and evaluated operation outcomes without comparison of pelvic organ function or recurrence rate of NSRH and RH, or trials not directly relevant to this review were excluded. Clinical trials missed the principle demographic or clinicopathological findings of cervical cancer patients, including age, body mass index (BMI), International Federation of Gynecology and Obstetrics (FIGO) stage, histological findings and tumor size were not included either. We evaluated the eligibility of all available studies independently without contacting the authors of selected clinical trials.

Statistical analysis was performed using Review Manager 5.3 software (Cochrane Collaboration). The mean and variance of data were calculated in studies of which only reported median and range data according to Hozo and colleagues' methods [10]. The risk ratio (RR) with 95\% confidence interval (CI) was calculated for data of dichotomous variables, and the mean difference (MD) with 95\% CI for data of continuous variables. Heterogeneity among studies was evaluated using the $\chi^{2}$ test, with significance set at $\mathrm{p}<0.05$. The value of $\mathrm{I}^{2} \leq 33 \%$ was considered as low heterogeneity [11]. Fixed effect model was used when $\mathrm{P} \geq 0.05$ and $\mathrm{I}^{2} \leq 33 \%$. If not, random effects model was used and sensitivity analysis was performed. Forest plots were used for results display.

\section{Results}

A total of 196 records were searched after duplicates removed. Of these, 131 records were excluded due to not directly relevant to this review. Within the further screened 65 records, 40 articles met the exclusion criteria. Based on the inclusion criteria we included 


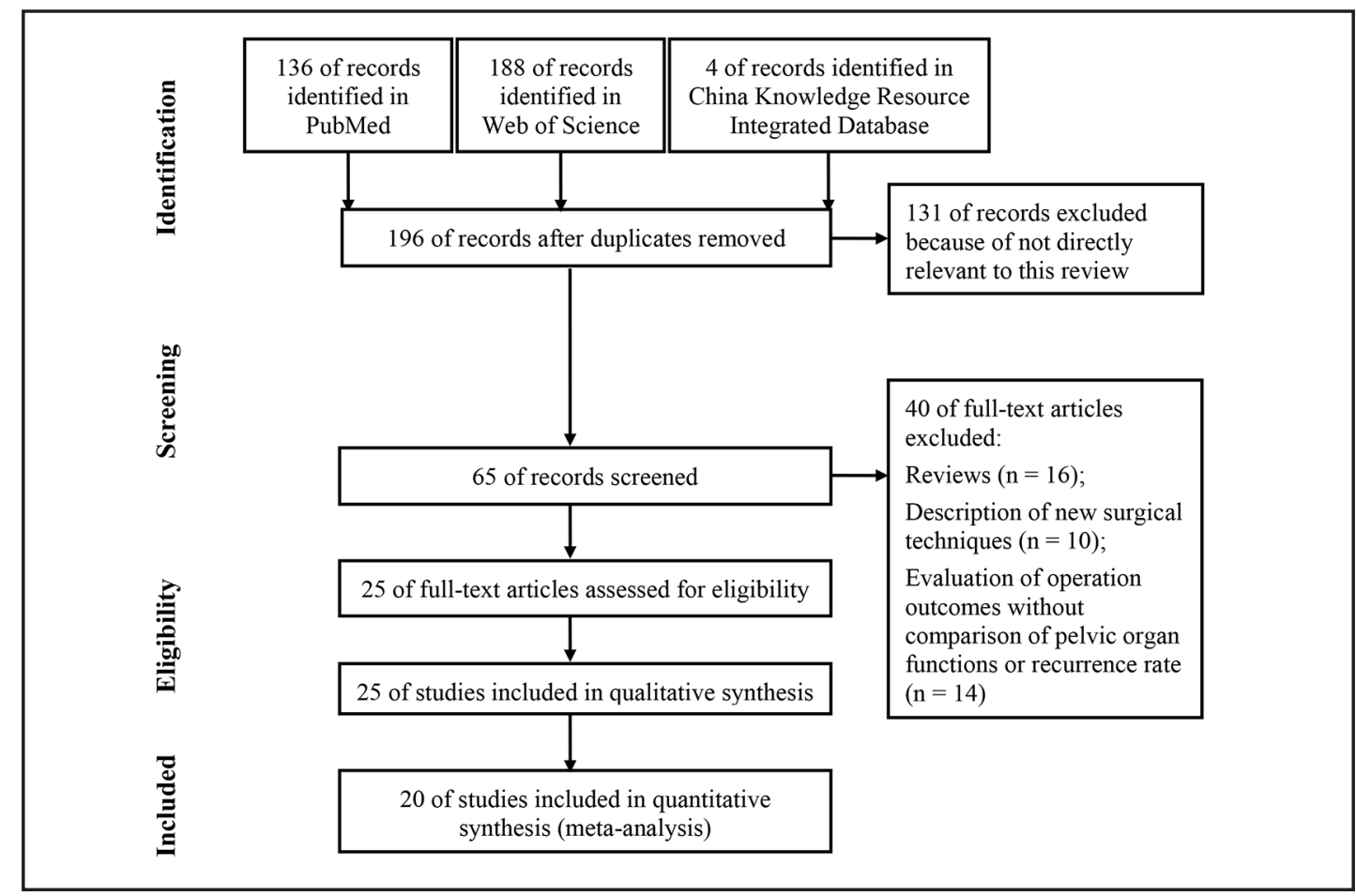

Fig. 1. Preferred reporting items for systematic reviews and meta-analyses (PRISMA) flow diagram for study selection.

the rest 25 articles in qualitative synthesis. After further assessment we finally included 20 studies (Fig. 1) in quantitative synthesis or for meta-analysis [12-31].

The risk of bias of the included 20 studies for meta-analysis was assessed using assessment tools in the Cochrane Handbook (Table 2). Patients' characteristics of the 20 included clinical trials were listed in Table 1.

Eight studies reported data on urinary incontinence after NSRH and RH $[14,18,19,25$, $26,28,30,31]$. Data extracted from the eight studies were meta-analyzed using a fixed effect model because of low heterogeneity among the trials $\left(\mathrm{P} \geq 0.05, \mathrm{I}^{2} \leq 33 \%\right)$. The analysis results demonstrated that NSRH technique had a significantly lower risk of bladder incontinence than RH ( $\mathrm{n}=409$, RR $=0.17,95 \%$ CI 0.09 to 0.31 , $\mathrm{P}<0.00001$; Fig. $2 \mathrm{a}$ ).

There were 11 studies compared mean time or median time of catheterization post NSRH and RH operation $[12,13,16,18-22,25,27,29]$. In order to make the data comparable, we calculated the mean time and standard deviation of data in 3 studies [13, 25, 27], which only reported the median time and range of catheterization by using the Hozo and colleagues' methods [10]. Meta-analysis of the 11 studies' data on mean time of catheterization indicated that NSRH had a significantly shorter mean time of catheterization than RH $(n=686, \mathrm{MD}=$ $-8.01,95 \%$ CI -10.64 to -5.38 , P < 0.00001; Fig. 2b). A random effects model was used in this meta-analysis due to high heterogeneity among studies $\left(\mathrm{P}<0.05, \mathrm{I}^{2}>33 \%\right)$.

Anorectal symptoms such as constipation and dyschezia were reported after RH [25]. However, there were only two studies with comparable data of constipation as an indicator of anorectal disorders after NSRH and RH $[18,25]$. Meta-analysis of the 2 studies didn't demonstrate a significant difference on constipation after NSRH and RH $(n=161, R R=0.54$, $95 \%$ CI 0.12 to 2.34, P > 0.05; Fig. 3a), although the 2 studies reported that NSRH had less or no anorectal issues than RH. There was only 1 study reported that NSRH had shorter mean time of first flatus and first defecation than RH, so meta-analysis was not used [16].

Sexual function was evaluated using the validated Female Sexual Function Index (FSFI) questionnaire, which assessed desire, arousal, lubrication, orgasm, satisfaction, and pain [15]. Two studies compared postoperative FSFI scores of NSRH and RH $[15,18]$. Meta- 
Table 1. General characteristics of included studies comparing nerve-sparing radical hysterectomy (NSRH) with radical hysterectomy $(\mathrm{RH})$ in cervical cancer. Data are reported as mean \pm SD or as median (range). Abbreviations: N, number; BMI, Body mass index; NR, not reported; NE, not extractable; A, adenocarcinoma; $\mathrm{S}$, squamous carcinoma; SA, adenosquamous carcinoma

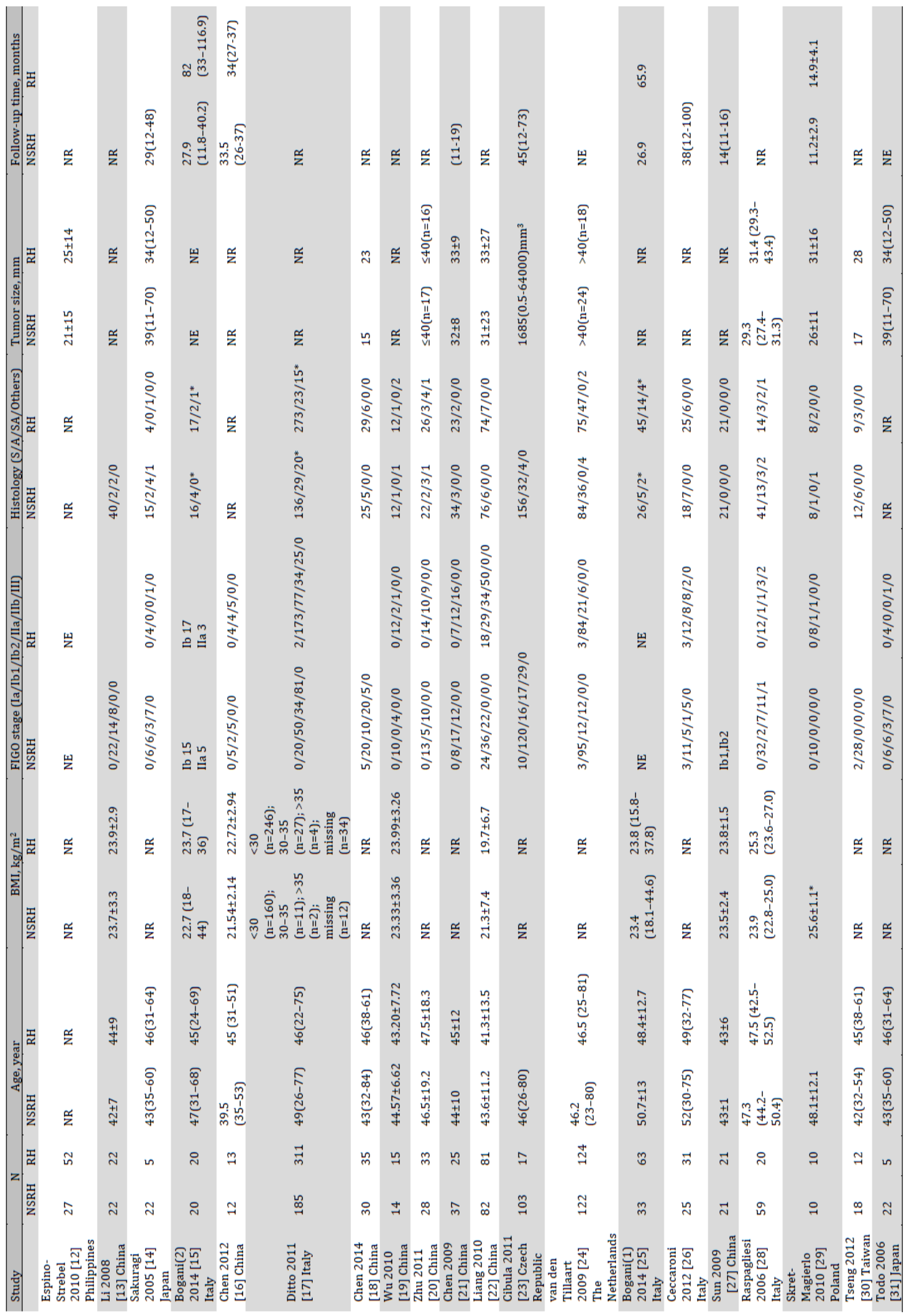




\begin{tabular}{|c|c|c|}
\hline \multirow{2}{*}{$\begin{array}{c}\text { Cellular Physiology } \\
\text { and Biochemistry }\end{array}$} & \multicolumn{2}{|c|}{ Cell Physiol Biochem 2016;38:1841-1850 } \\
\hline & $\begin{array}{l}\text { DOI: 10.1159/000443122 } \\
\text { Publised donline: May y9 } 2016\end{array}$ & $\begin{array}{l}02016 \text { The Author(s). Published by S. Karger AG, Basel } \\
\text { wwwwkargercom/cpb }\end{array}$ \\
\hline
\end{tabular}

Table 2. Quality assessment of included studies based on the guidelines of Cochrane Handbook for Systematic Reviews of Interventions

\begin{tabular}{|c|c|c|c|c|c|c|}
\hline Study & $\begin{array}{l}\text { Random } \\
\text { sequence } \\
\text { generation }\end{array}$ & $\begin{array}{l}\text { Allocation } \\
\text { concealment }\end{array}$ & $\begin{array}{l}\text { Blinding of } \\
\text { participants and } \\
\text { personnel }\end{array}$ & $\begin{array}{l}\text { Blinding of } \\
\text { outcome } \\
\text { assessment }\end{array}$ & $\begin{array}{l}\text { Incomplete } \\
\text { outcome data }\end{array}$ & Selective reporting \\
\hline \multicolumn{7}{|c|}{ Randomized controlled trials } \\
\hline Chen 2012 [16] China & Unclear risk & Unclear risk & Unclear risk & Unclear risk & Low risk & Unclear risk \\
\hline Chen 2014 [18] China & Unclear risk & Unclear risk & Unclear risk & Unclear risk & Low risk & Unclear risk \\
\hline Wu 2010 [19] China & Unclear risk & Unclear risk & Unclear risk & Unclear risk & Low risk & Unclear risk \\
\hline \multicolumn{7}{|c|}{ Non-randomized controlled trials } \\
\hline $\begin{array}{l}\text { Espino-Strebel } 2010 \text { [12] } \\
\text { Philippines }\end{array}$ & Unclear risk & Unclear risk & Unclear risk & Unclear risk & Low risk & Unclear risk \\
\hline Li 2008 [13] China & Low risk & Low risk & Unclear risk & Unclear risk & Low risk & Unclear risk \\
\hline Sakuragi 2005 [14] Japan & Low risk & Low risk & Unclear risk & Unclear risk & Low risk & Unclear risk \\
\hline Bogani(2) 2014 [15] Italy & Unclear risk & Unclear risk & Unclear risk & Unclear risk & Low risk & Unclear risk \\
\hline Ditto 2011 [17] Italy & Low risk & Low risk & Unclear risk & Unclear risk & Low risk & Unclear risk \\
\hline Zhu 2011 [20] China & Low risk & Low risk & Unclear risk & Unclear risk & Low risk & Unclear risk \\
\hline Chen 2009 [21] China & Low risk & Low risk & Unclear risk & Unclear risk & Low risk & Unclear risk \\
\hline Liang 2010 [22] China & Low risk & Low risk & Unclear risk & Unclear risk & Low risk & Unclear risk \\
\hline $\begin{array}{l}\text { Cibula } 2011 \text { [23] Czech } \\
\text { Republic }\end{array}$ & Low risk & Low risk & Unclear risk & Unclear risk & Low risk & Unclear risk \\
\hline $\begin{array}{l}\text { van den Tillaart } 2009 \\
\text { [24] The Netherlands }\end{array}$ & Low risk & Low risk & Unclear risk & Unclear risk & Low risk & Unclear risk \\
\hline Bogani(1) 2014 [25] Italy & Low risk & Low risk & Unclear risk & Unclear risk & Low risk & Unclear risk \\
\hline Ceccaroni 2012 [26] Italy & Low risk & Low risk & Unclear risk & Unclear risk & Low risk & Unclear risk \\
\hline Sun 2009 [27] China & Low risk & Low risk & Unclear risk & Unclear risk & Low risk & Unclear risk \\
\hline $\begin{array}{l}\text { Raspagliesi } 2006 \text { [28] } \\
\text { Italy }\end{array}$ & Low risk & Low risk & Unclear risk & Unclear risk & Low risk & Unclear risk \\
\hline $\begin{array}{l}\text { Skret-Magierlo } 2010 \text { [29] } \\
\text { Poland }\end{array}$ & Low risk & Low risk & Unclear risk & Unclear risk & Low risk & Unclear risk \\
\hline Tseng 2012 [30] Taiwan & Low risk & Low risk & Unclear risk & Unclear risk & Low risk & Unclear risk \\
\hline Todo 2006 [31] Japan & Low risk & Low risk & Unclear risk & Unclear risk & Low risk & Unclear risk \\
\hline
\end{tabular}

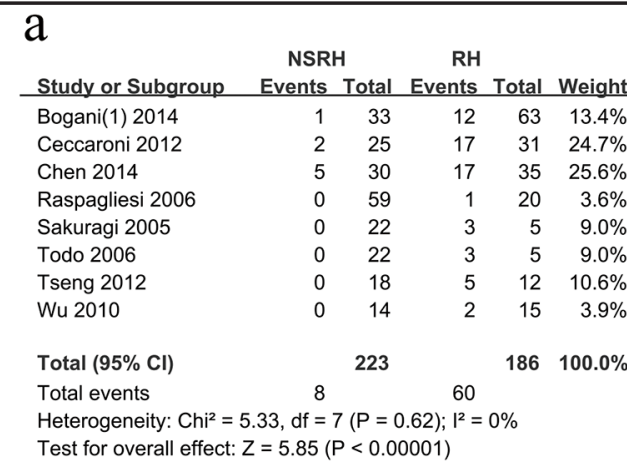

$\begin{array}{lc}\text { Risk Ratio } & \text { Risk Ratio } \\ \text { M-H. Fixed. } 95 \% \mathrm{Cl} & \text { M-H. Fixed } 95 \%\end{array}$

. Fixed. 95\% C

$0.15[0.04,0.57]$

$0.34[0.14,0.82]$

$0.12[0.00,2.75]$

$0.04[0.00,0.63]$

$0.04[0.00,0.63]$

$0.06[0.00,1.03]$

$0.21[0.01,4.09]$

$0.17[0.09,0.31]$

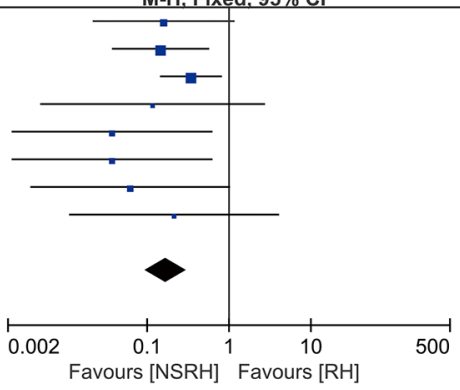

b

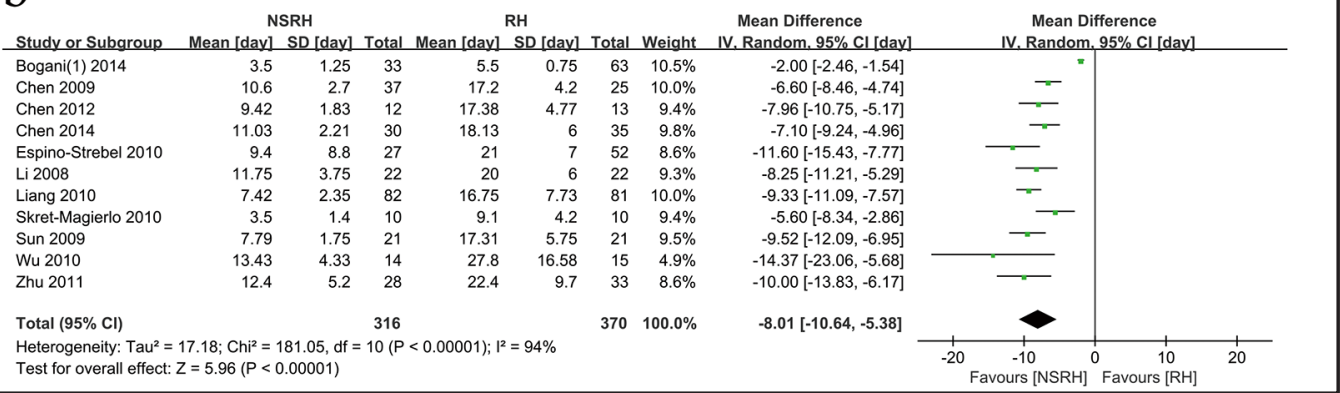

Fig. 2. Forest plots comparing nerve-sparing radical hysterectomy (NSRH) with radical hysterectomy (RH) in terms of (a) bladder dysfunction, (b) time of catheterization.

analysis of the 2 studies demonstrated that NSRH had significant higher FSFI scores than RH, which suggested that NSRH might reduce sexual dissatisfaction $(n=105, M D=5.83,95 \%$ CI 4.35 to 7.32 , $\mathrm{P}<0.00001$; Fig. 3b). Fixed effect model was used for meta-analysis of anorectal and sexual functions due to low heterogeneity among the clinical trials $\left(\mathrm{P} \geq 0.05, \mathrm{I}^{2} \leq 33 \%\right)$.

Local recurrence was defined as pelvic and vaginal recurrences. We included 7 studies with comparison of postoperative local recurrence data of NSRH and RH $[14,16,17,23$ $25,31]$. Fixed effect model was used for meta-analysis of local recurrences due to low heterogeneity among the trials $\left(\mathrm{P} \geq 0.05, \mathrm{I}^{2} \leq 33 \%\right)$. The analysis of 7 studies indicated that 


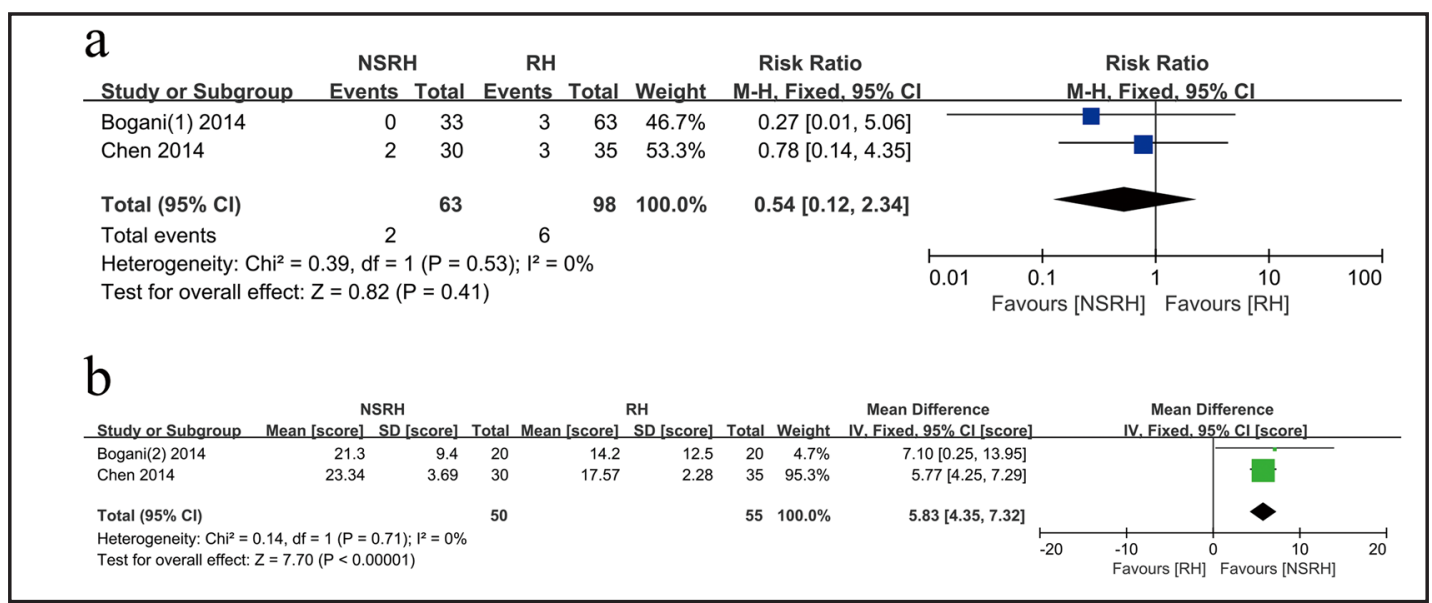

Fig. 3. Forest plots comparing nerve-sparing radical hysterectomy (NSRH) with radical hysterectomy (RH) in terms of (a) anorectal function, (b) sexual function.

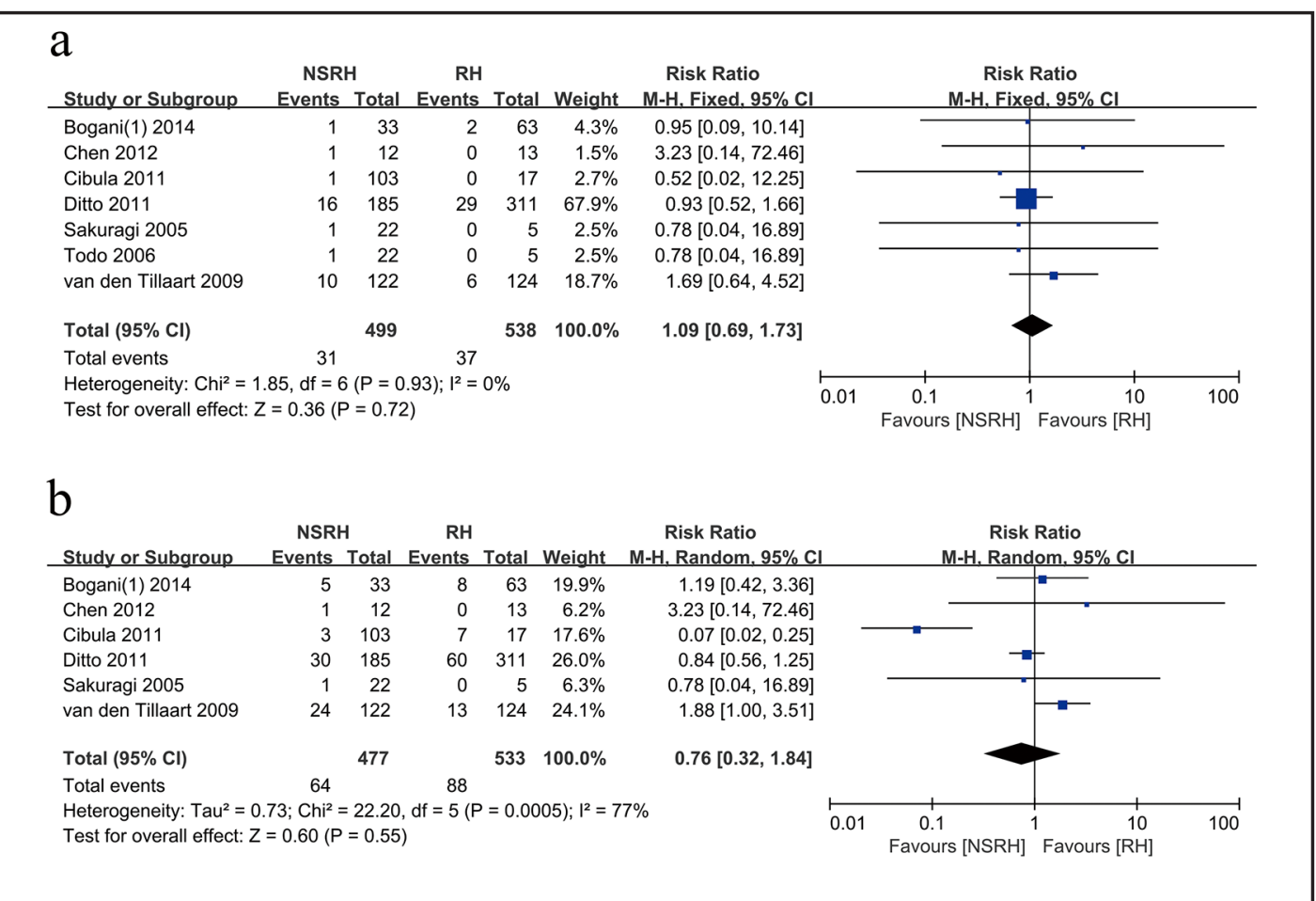

Fig. 4. Forest plots comparing nerve-sparing radical hysterectomy (NSRH) with radical hysterectomy (RH) in terms of (a) local recurrence, (b) overall recurrence.

the local recurrence rate of NSRH and RH technique was similar with no significant difference ( $\mathrm{n}=1037, \mathrm{RR}=1.09,95 \% \mathrm{CI} 0.69$ to $1.73, \mathrm{P}>0.05$; Fig. $4 \mathrm{a}$ ).

The overall recurrence included any postoperative recurrence of NSRH and RH. Six studies met our inclusion criteria reported overall recurrence rate $[14,16,17,23-25]$. We extracted the overall recurrence data and used random effects model in this meta-analysis due to high heterogeneity among studies ( $\left.\mathrm{P}<0.05, \mathrm{I}^{2}>33 \%\right)$. The analysis result didn't show any significant differences between the overall recurrences of NSRH and RH either (n $=1010, \mathrm{RR}=0.76,95 \% \mathrm{CI} 0.32$ to $1.84, \mathrm{P}>0.05$; Fig. $4 \mathrm{~b}$ ). 


\section{Cellular Physiology Cell Physiol Biochem 2016;38:1841-1850

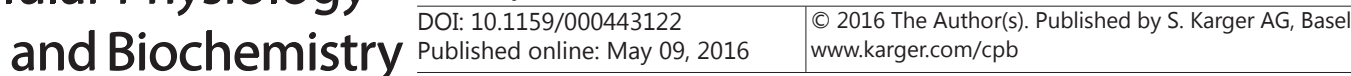 \\ Xue/Zhu/Teng: Comparison of NSRH and RH}

\section{Discussion}

Main Findings

Since there were a bunch of variables indicating bladder dysfunction including urinary incontinence, urinary urgency, nocturia, loss of bladder sensation and straining to void, we chose the widely reported urinary incontinence as a relatively comparable indicator for bladder dysfunction [32]. Similarly, we chose the widely reported postoperative mean time of catheterization as the indicator of bladder function recovery. After analyzing 8 studies reported urinary incontinence and 11 studies reported mean time of catheterization respectively, we found that NSRH could significantly decrease urinary incontinence and postoperative mean time of catheterization compared to $\mathrm{RH}$. These results suggested that NSRH was an effective surgical technique with better postoperative bladder function than $\mathrm{RH}$, which was in line with Long and colleagues' findings [33].

NSRH was also believed to have better anorectal function in cervical cancer survivors. ${ }^{33}$ Although anorectal function outcomes were reported by several studies, we only found 2 relevant studies with comparable data on anorectal dysfunction [18, 25]. Due to various parameters indicating anorectal dysfunction such as constipation, defecation straining, stool incontinence and flatulence incontinence, we chose constipation as the comparable parameter of anorectal dysfunction in this review [32]. However, meta-analysis of anorectal dysfunction data of the 2 studies showed no significant difference between NSRH and RH, which might be due to the relatively small number of studies and participants. Since there was only 1 clinical trial with comparable data of the mean time of first flatus and first defecation, which indicated anorectal function recovery, we couldn't meta-analysis these data [16].

Sexual function of cervical cancer survivors was often assessed via several kinds of validated questionnaires, including the FSFI Questionnaire, the Dutch Gynecologic Leiden Questionnaire, and the Functional Assessment of Cancer Therapy-Cervix (FACT-Cx) Questionnaire, the European Organization for Research and Treatment of Cancer, Quality of Life Questionnaire with the cervical cancer module (EORTC QLQ-CX24) [15, 18, 34-36]. In order to extract comparable data on postoperative sexual function of cervical patients, we included 2 studies used the same FSFI questionnaire $[15,18]$. The meta-analysis of total FSFI scores of cervical cancer survivors in the 2 studies indicated that both NSRH and RH led to lower sexual life satisfaction. Patients underwent NSRH showed significantly higher total FSFI scores which suggested relatively better satisfaction with postoperative sexual function than RH.

As a popular surgical technique sparing the pelvic autonomic nerves without compromising radicality, NSRH was reported to have similar clinical safety and extent of resection with RH for early stage cervical cancers treatment [33, 37]. As Basaran and colleagues reported that there were neither adequate nor statistically relevant evidence addressing the oncologic safety of NSRH over that of RH, due to the scarcity and heterogeneity of effect estimates in different trials [8]. We focused on the recurrence rate of cervical cancer after NSRH and RH, which was regarded as a main outcome measure.

Seven studies were included in this review for a meta-analysis with local recurrence rate data $[14,16,17,23-25,31]$, of which six studies reported overall recurrence rate data as well $[14,16,17,23-25]$. Meta-analysis of these local and overall recurrence rate data didn't show significant differences after NSRH and RH procedures. Several evidence like the reviewer mentioned above did suggest that these two surgical techniques might have similar long term outcomes [33, 38-41]. So we included studies using laparotomy-based or laparoscopy-based approaches in this study and analyzed the outcomes of NSRH and RH without differentiating their specific approaches. These findings on recurrence rate especially the overall recurrence rate should be interpreted cautiously because of the relatively high heterogeneity among included individual studies.

\section{Strengths and Limitations}

The major strengths of this study were (1) Used large data sets and found significant differences in outcome for bladder and sexual function; (2) Used validated methodology and KARGER 


\section{Cellular Physiology Cell Physiol Biochem 2016;38:1841-1850

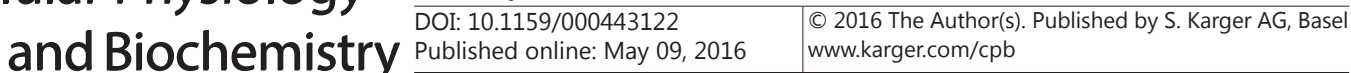 \\ Xue/Zhu/Teng: Comparison of NSRH and RH}

statistical design for analysis. The conclusions of this review were based on comparable data that could be extracted for meta-analysis. However, there were a bunch of other variables reported as pelvic organ function parameters that we didn't choose because of their relatively non-comparability. Anorectal function and sexual function findings were based on just two studies, which might render these meta-analysis results less reliable because of statistical power issues.

\section{Interpretation}

The vast majority of included studies showed better results for NSRH. Meta-analysis of these existing clinical data confirmed these findings. Although NSRH remains attractive for cervical cancer patients and gynecologic surgeons based on current clinical trials, our findings in this review should be further verified in larger clinical trials with more extensive comparable data.

\section{Conclusion}

In conclusion, this review and meta-analysis provided evidence that NSRH might be a potentially promising surgical approach for early stage cervical cancer patients with relatively better pelvic organ function and similar recurrence rate compared to RH. More clinical trials with larger participants are needed to verify the efficacy and safety of NSRH before it is recommended as a standard approach for cervical cancer treatment.

\section{Acknowledgements}

We thank our colleagues for their helpful advice during the course of this study.

\section{Disclosure Statement}

The authors declared no conflict of interests.

\section{References}

1 World Health Organization: The global burden of disease: 2004 update. Geneva: World Health Organization 2008.

2 Dursun P, Ayhan A, Kuscu E: Nerve-sparing radical hysterectomy for cervical carcinoma. Crit Rev Oncol Hematol 2009;70:195-205.

3 Fujii S: Original film of the Okabayashi's radical hysterectomy by Okabayashi himself in 1932, and two films of the precise anatomy necessary for nerve-sparing Okabayashi's radical hysterectomy clarified by Shingo Fujii. Int J Gynecol Cancer 2008;18:383-385.

4 Maas CP, Trimbos JB, DeRuiter MC, van de Velde CJ, Kenter GG: Nerve sparing radical hysterectomy: latest developments and historical perspective. Crit Rev Oncol Hematol 2003;48:271-279.

5 Fujii S, Takakura K, Matsumura N, Higuchi T, Yura S, Mandai M, Baba T, Yoshioka S: Anatomic identification and functional outcomes of the nerve sparing Okabayashi radical hysterectomy. Gynecol Oncol 2007;107:413.

6 Hockel M, Konerding MA, Heussel CP: Liposuction-assisted nerve-sparing extended radical hysterectomy: oncologic rationale, surgical anatomy, and feasibility study. Am J Obstet Gynecol 1998;178:971-976.

7 Puntambekar SP, Patil A, Joshi SN, Rayate NV, Puntambekar SS, Agarwal GA: Preservation of autonomic nerves in laparoscopic total radical hysterectomy. J Laparoendosc Adv Surg Tech A 2010;20:813-819.

8 Basaran D, Dusek L, Majek O, Cibula D: Oncological outcomes of nerve-sparing radical hysterectomy for cervical cancer: a systematic review. Ann Surg Oncol 2015;22:3033-3040. 


\section{Cellular Physiology Cell Physiol Biochem 2016;38:1841-1850 \begin{tabular}{l|l} 
DOI: 10.1159/000443122 & $\begin{array}{l}\text { O 2016 The Author(s). Published by S. Karger AG, Basel } \\
\text { www.karger.com/cpb }\end{array}$
\end{tabular} \\ Xue/Zhu/Teng: Comparison of NSRH and RH}

9 Moher D, Liberati A, Tetzlaff J, Altman DG, Group P: Preferred reporting items for systematic reviews and meta-analyses: the PRISMA statement. BMJ 2009;339:b2535.

10 Hozo SP, Djulbegovic B, Hozo I: Estimating the mean and variance from the median, range, and the size of a sample. BMC Med Res Methodol 2005;5:13.

11 Higgins JP, Thompson SG: Quantifying heterogeneity in a meta-analysis. Stat Med 2002;21:1539-1558.

12 Espino-Strebel EE, Luna JT, Domingo EJ: A comparison of the feasibility and safety of nerve-sparing radical hysterectomy with the conventional radical hysterectomy. Int J Gynecol Cancer 2010;20:1274-1283.

13 Li B, Zhang R, Wu LY, Zhang GY, Li X, Yu GZ: [A prospective study on nerve-sparing radical hysterectomy in patients with cervical cancer]. Zhonghua Fu Chan Ke Za Zhi 2008;43:606-610.

14 Sakuragi N, Todo Y, Kudo M, Yamamoto R, Sato T: A systematic nerve-sparing radical hysterectomy technique in invasive cervical cancer for preserving postsurgical bladder function. Int J Gynecol Cancer 2005;15:389-397.

15 Bogani G, Serati M, Nappi R, Cromi A, di Naro E, Ghezzi F: Nerve-sparing approach reduces sexual dysfunction in patients undergoing laparoscopic radical hysterectomy. J Sex Med 2014;11:3012-3020.

16 Chen C, Li W, Li F, Liu P, Zhou J, Lu L, Su G, Li X, Guo Y, Huang L: Classical and nerve-sparing radical hysterectomy: an evaluation of the nerve trauma in cardinal ligament. Gynecol Oncol 2012;125:245-251.

17 Ditto A, Martinelli F, Mattana F, Reato C, Solima E, Carcangiu M, Haeusler E, Mariani L, Raspagliesi F: Class III nerve-sparing radical hysterectomy versus standard class III radical hysterectomy: an observational study. Ann Surg Oncol 2011;18:3469-3478.

18 Chen L, Zhang WN, Zhang SM, Yang ZH, Zhang P: Effect of laparoscopic nerve-sparing radical hysterectomy on bladder function, intestinal function recovery and quality of sexual life in patients with cervical carcinoma. Asian Pac J Cancer Prev 2014;15:10971-10975.

19 Wu J, Liu X, Hua K, Hu C, Chen X, Lu X: Effect of nerve-sparing radical hysterectomy on bladder function recovery and quality of life in patients with cervical carcinoma. Int J Gynecol Cancer 2010;20:905-909.

20 Zhu T, Yu AJ, Shou HF, Chen X, Zhu JQ, Yang ZY, Zhang P, Gao YL: [Feasibility of unilateral or bilateral nervesparing radical hysterectomy in patients with cervical cancer and evaluation of the post-surgery recovery of the bladder and rectal function]. Zhonghua Zhong Liu Za Zhi 2011;33:53-57.

21 Chen Y, Li Y, Xu HC, Li JN, Li YY, Liang ZQ: [Laparoscopic anatomical nerve sparing radical hysterectomy for cervical cancer: a clinical analysis of 37 cases]. Zhonghua Fu Chan Ke Za Zhi 2009;44:359-363.

22 Liang Z, Chen Y, Xu H, Li Y, Wang D: Laparoscopic nerve-sparing radical hysterectomy with fascia space dissection technique for cervical cancer: description of technique and outcomes. Gynecol Oncol 2010;119:202-207.

23 Cibula D, Pinkavova I, Dusek L, Slama J, Zikan M, Fischerova D, Freitag P, Dundr P: Local control after tailored surgical treatment of early cervical cancer. Int J Gynecol Cancer 2011;21:690-698.

24 van den Tillaart SA, Kenter GG, Peters AA, Dekker FW, Gaarenstroom KN, Fleuren GJ, Trimbos JB: Nervesparing radical hysterectomy: local recurrence rate, feasibility, and safety in cervical cancer patients stage IA to IIA. Int J Gynecol Cancer 2009;19:39-45.

25 Bogani G, Cromi A, Uccella S, Serati M, Casarin J, Pinelli C, Nardelli F, Ghezzi F: Nerve-sparing versus conventional laparoscopic radical hysterectomy: a minimum 12 months' follow-up study. Int J Gynecol Cancer 2014;24:787-793.

26 Ceccaroni M, Roviglione G, Spagnolo E, Casadio P, Clarizia R, Peiretti M, Bruni F, Peters I, Aletti G: Pelvic dysfunctions and quality of life after nerve-sparing radical hysterectomy: a multicenter comparative study. Anticancer Res 2012;32:581-588.

27 Sun L, Wu LY, Zhang WH, Li XG, Song Y, Zhang X: [Preliminary study of nerve sparing radical hysterectomy in patients with cervical cancer]. Zhonghua Zhong Liu Za Zhi 2009;31:607-611.

28 Raspagliesi F, Ditto A, Fontanelli R, Zanaboni F, Solima E, Spatti G, Hanozet F, Vecchione F, Rossi G, Kusamura S: Type II versus Type III nerve-sparing radical hysterectomy: comparison of lower urinary tract dysfunctions. Gynecol Oncol 2006;102:256-262.

29 Skret-Magierlo J, Narog M, Kruczek A, Kluza R, Kluz T, Magon T, Skret A, Wicherek L: Radical hysterectomy during the transition period from traditional to nerve-sparing technique. Gynecol Oncol 2010;116:502505.

30 Tseng CJ, Shen HP, Lin YH, Lee CY, Wei-Cheng Chiu W: A prospective study of nerve-sparing radical hysterectomy for uterine cervical carcinoma in Taiwan. Taiwan J Obstet Gynecol 2012;51:55-59. 


\section{Cellular Physiology Cell Physiol Biochem 2016;38:1841-1850 \begin{tabular}{ll|l} 
DOI: 10.1159/000443122 & $\begin{array}{l}\text { O 2016 The Author(s). Published by S. Karger AG, Basel } \\
\text { www.karger.com/cpb }\end{array}$ \\
\cline { 2 - 3 }
\end{tabular} \\ Xue/Zhu/Teng: Comparison of NSRH and RH}

31 Todo Y, Kuwabara M, Watari H, Ebina Y, Takeda M, Kudo M, Yamamoto R, Sakuragi N: Urodynamic study on postsurgical bladder function in cervical cancer treated with systematic nerve-sparing radical hysterectomy. Int J Gynecol Cancer 2006;16:369-375.

32 Cibula D, Velechovska P, Slama J, Fischerova D, Pinkavova I, Pavlista D, Dundr P, Hill M, Freitag P, Zikan M: Late morbidity following nerve-sparing radical hysterectomy. Gynecol Oncol 2010;116:506-511.

33 Long Y, Yao DS, Pan XW, Ou TY: Clinical efficacy and safety of nerve-sparing radical hysterectomy for cervical cancer: a systematic review and meta-analysis. PLoS One 2014;9:e94116.

34 Sowa E, Kuhnt S, Hinz A, Schroder C, Deutsch T, Geue K: Postoperative Health-Related Quality of Life of Cervical Cancer Patients - A Comparison between the Wertheim-Meigs Operation and Total Mesometrial Resection (TMMR). Geburtshilfe Frauenheilkd 2014;74:670-676.

35 Pieterse QD, Kenter GG, Maas CP, de Kroon CD, Creutzberg CL, Trimbos JB, Ter Kuile MM: Self-reported sexual, bowel and bladder function in cervical cancer patients following different treatment modalities: longitudinal prospective cohort study. Int J Gynecol Cancer 2013;23:1717-1725.

36 Ditto A, Martinelli F, Borreani C, Kusamura S, Hanozet F, Brunelli C, Rossi G, Solima E, Fontanelli R, Zanaboni F, Grijuela B, Raspagliesi F: Quality of life and sexual, bladder, and intestinal dysfunctions after class III nerve-sparing and class II radical hysterectomies: a questionnaire-based study. Int J Gynecol Cancer 2009;19:953-957.

37 Charoenkwan K, Srisomboon J, Suprasert P, Tantipalakorn C, Kietpeerakool C: Nerve-sparing class III radical hysterectomy: a modified technique to spare the pelvic autonomic nerves without compromising radicality. Int J Gynecol Cancer 2006;16:1705-1712.

38 Nam JH, Park JY, Kim DY, Kim JH, Kim YM, Kim YT: Laparoscopic versus open radical hysterectomy in earlystage cervical cancer: long-term survival outcomes in a matched cohort study. Ann Oncol 2012;23:903-911.

39 Bogani G, Cromi A, Uccella S, Serati M, Casarin J, Pinelli C, Ghezzi F: Laparoscopic versus open abdominal management of cervical cancer: long-term results from a propensity-matched analysis. J Minim Invasive Gynecol 2014;21:857-862.

40 Bogani G, Cromi A, Serati M, Di Naro E, Uccella S, Donadello N, Ghezzi F: Predictors of postoperative morbidity after laparoscopic versus open radical hysterectomy plus external beam radiotherapy: a propensity-matched comparison. J Surg Oncol 2014;110:893-898.

41 Park JY, Kim DY, Kim JH, Kim YM, Kim YT, Nam JH: Laparoscopic versus open radical hysterectomy for elderly patients with early-stage cervical cancer. Am J Obstet Gynecol 2012;207:195 e191-198. 